LETTERS TO THE EDITOR.

[The Editor does not hold himself responsible for opinions expressed by his correspondents. Neither can he undertake to return, or to correspond with the writers of, rejected manuscripts intended for this or any other part of NATURE. No notice is taken of anonymous communications.]

Visibility of Interference Fringes and the Double Slit.

THE writer has found the following simple arrangement well adapted for the study of the visibility of fringes arising from a double slit and a "source" slit of variable width. A double slit, ruled without any special care on a piece of old photographic negative, was placed on the table of a spectrometer after the usual adjustments had been made. With this arrangement and a sodium flame (Mecker burner) as the source of light, no difficulty was experienced in observing the disappearance and reappearance of the fringes, with gradually decreasing visibility, some seven times.

In the experiment as ordinarily performed (V. Mann's "Manual of Advanced Optics," p. 27) the source slit is at such a distance from the double slit as to render the experiment impracticable, or at least very inconvenient, in many laboratories. Ordinarily, too, a strong source of light is used, whereas the above arrangement permits the use of a monochromatic source. It provides, further, a very simple experiment by means of which the student beginning the study of advanced optics may obtain concrete ideas on the somewhat difficult subject of visibility. With a little practice, estimates of the visibility at successive stages may be made, and the corresponding visibility curve plotted.

To make quantitative measurements, a graduated wheel was attached to the slit of an ordinary Wilson spectrometer, and afterwards calibrated by the aid of a travelling microscope. By this means the width of the slit corresponding to the places of disappearance of the fringes or to any stage of visibility could be read off directly, and in a short time a complete set of measurements taken. The following readings will give an idea of the quantitative value of the experiment :-

Width of double slit $(b) \quad \ldots \quad \ldots=0.903 \mathrm{~mm}$.

Focal length of lens of collimator $(\dddot{f})=\mathrm{I} 66$,

Mean value of increase in slit width

$(w)$ for successive orders of zero

$\begin{array}{lllll}\text { visibility } \quad \ldots & \ldots & \ldots & \ldots & =0.107,\end{array}$

From which $\lambda=\frac{b w}{f}=0.000582 \mathrm{~mm}$.

The quantity $w$ is accurate to about I per cent. A more accurately calibrated spertrometer slit than was at the disposal of the writer would permit doubtless of greater accuracy in the measurements.

J. K. Robertson.

Queen's University, Kingston, Canada.

Relations between the Spectra of X-Rays.

Kossel has found the following relations between the frequencies of the X-ray spectra :-

$$
\begin{aligned}
\mathrm{L}_{\alpha} & =\mathrm{K}_{\beta}-\mathrm{K}_{\alpha} \\
\mathrm{M}_{\alpha} & =\mathrm{L}_{\gamma}-\mathrm{L}_{\alpha}
\end{aligned}
$$

As the result of recent measurements, it is known that all these series consist of many more lines. According to $T$ Malmer the relation (A) of Kossel must take the form :-

$$
\mathrm{L}_{\alpha_{1}}=\mathrm{K}_{\beta_{1}}-\mathrm{K}_{\alpha_{2}}
$$

Adopting the values for the wave-length given by NO. 249I, VOL. 99]
M. Siegbahn (Jahrb. d. Radioakt, u. Elektr.), we have, moreover, instead of $(B)$,

$$
\begin{aligned}
& \mathrm{M}_{\beta}=\mathrm{L}_{\gamma_{1}}-\mathrm{L}_{\beta_{4}} \text {. . . . . (2) } \\
& \mathrm{M}_{\gamma_{1}}=\mathrm{L}_{\gamma_{2}}-\mathrm{L}_{\beta_{1}} \text {. . . . . (3) }
\end{aligned}
$$

I will here also remark that the following relations hold very exactly through all the elements :- -

$$
\left.\begin{array}{rl}
\mathrm{L}_{\alpha_{2}}-\mathrm{L}_{\beta_{2}} & =\mathrm{L}_{\beta_{1}}-\mathrm{L}_{\gamma_{1}} \\
& =\mathrm{L}_{\beta_{3}}-\mathrm{L}_{\gamma_{2}}+\Delta
\end{array}\right\} .
$$

where $\Delta$ is a constant.

In order to account for these relations, especially (4), Bohr's theoretical formula should be modified as follows :-

$$
\nu=\nu_{0}\left\{\frac{\left(\mathrm{N}-\mathrm{C}_{1}\right)^{2}}{\left(n_{1}+\mu_{1}\right)^{2}}-\frac{\left(\mathrm{N}-\mathrm{C}_{2}\right)^{2}}{\left(n_{2}+\mu_{2}\right)^{2}}\right\}
$$

$\mathrm{N}$ being the atomic number, $n_{1}$ and $n_{2}$ certain integers. It should be supposed that $\mathrm{N}-\mathrm{C}_{1}$ and $\mathrm{N}-\mathrm{C}_{2}$ represent the numbers of electric quanta contained in the "effective" nucleus charge. The curve in Moseley's diagram shows further that $\mu_{1}$ and $\mu_{2}$ are not absolute constants, but vary gradually from element to element.

Physical Institute, Sendai, Japan, April, Ig17.

\section{METEOROLOGY AND AVIATION.}

\section{A RECENT lecture by Lord Montagu of} A Beaulieu to the Aeronautical Society has directed attention to the possibility after the war of conveying mails and passengers, and perhaps goods, from place to place by aeroplanes. In suitable weather such transit should present no difficulty save that of expense, provided that landing places can be found in such positions that the stages may not be too long, but it is obvious that the weather is, and must remain, a very important factor for many years to come.

Since the foundation of the Meteorological Office under Admiral Fitzroy a large part of its business has been the issuing of storm warnings at certain selected coast stations for the benefit of shipping; and there is no doubt that such warnings during the fifty years or so in which they have been issued have been of great use, and indeed are so still. But the gradual displacement of sails by steam and the increase of size, with the greater trustworthiness of the engines, have rendered vessels far less dependent upon the weather than they were in Admiral Fitzroy's time, and in these days it is seldom that any regular passenger boat fails to make its passage, though it may be more or less delayed by bad weather. The case is likely to be different with aeroplanes if they are to take the place of mail steamers, and a heavy responsibility will be thrown upon the Meteorological Office or upon whatever body undertakes to issue forecasts for their guidance.

The kinds of weather inimical to aviation are too much wind, low cloud, and fog, and of these fog is perhaps the worst, as it is also in the case of shipping. The ways in which wind affects an aeroplane are various. There is the difficulty of starting and landing, but the days on which this is serious are not numerous, even in a windy country like England. But still there are days when landing is unsafe, and it is the misfortune 
with an aeroplane that it must in some way or other come to the earth as soon as its stock of petrol is exhausted. It cannot, like a ship outside a port with a dangerous bar, wait until conditions are more favourable; it must come down, whatever the risk. Once in the air, a steady wind has no effect upon the flying of an aeroplane, although it has a great effect upon the direction of the course. So much misapprehension exists on this point that it cannot be put too clearly. First, however, it must be stated frankly that a perfectly steady wind does not exist in practice, but the ordinary wind becomes more and more steady as the height increases, and in so far as the drift of an aeroplane is concerned it has the same effect as a steady wind of the same mean velocity.

The pilot, therefore, if the earth is hidden from him by a sheet of clouds, is absolutely and entirely ignorant of the strength and direction of the wind in which he is flying; it is just the same to him if it be a dead calm or if it be blowing at the rate of a hundred miles an hour from the east or from the west; he is, indeed, as unconscious of the motion which he is sharing with the air as he is of his daily revolution at a rate in these latitudes of some 600 miles an hour round the axis of the earth. But the effect upon the drift of his machine may be very considerable, and as he does not know what it is he cannot allow for it. The sailor is also concerned with the drift of his vessel, but he has in general a fairly good knowledge of how much it is; the currents due to the tide can be predicted, and the leeway due to wind can be estimated, but it is not so with the airman. Moreover, the rate of drift of a vessel is mostly small in comparison with her motion through the water, but in exceptional instances the velocity of the wind may equal the velocity of the aeroplane.

Thus Glasgow lies very close to a point 400 miles due north of Plymouth, and an aeroplane leaving Plymouth and flying due north at eighty miles an hour would find itself close to Glasgow in five hours' time. Should, however, a strong west wind be blowing of which the pilot did not know, and also clouds so that he could not see the earth, he would, if steering by compass, find himself in five hours' time over the North Sea, and quite possibly much nearer to the Danish than to the English coast. In the present state of our knowledge he could obtain information at starting of the general direction and strength of the wind, but not in such detail that he could hit off Glasgow within Ioo or 200 miles. If he could see the ground he could ascertain that he was not travelling in the way his machine was pointing, and would thus become aware of his drift, but if he could see the ground he could steer by the known landmarks. There would be few landmarks over the sea, but the appearance of the surface should give him information as to the strength of the wind, and also of its direction.

Hence it seems likely that in countries like England, where clouds prevail, long-distance flight, if it is to be carried on at regular times day after day, will have to be at low elevations. About $3000 \mathrm{ft}$. is the usual height of the winter cloud NO. 249I, VOL. 99] sheet, but it may on occasion easily descend to $2000 \mathrm{ft}$.

Wind, therefore, though when it is steady and in a favourable direction it may be of assistance for a journey in its own direction, will in general be a hindrance to aerial navigation, and when combined with low clouds may become an insuperable hindrance. In cases where its velocity and direction can be accurately foretold, the difficulty about allowing for the drift can be overcome, but such precise forecast is not yet practicable.

A gusty wind introduces difficulties of its own; the so-called holes in the air, of which one heard so much in the early days of aviation, were due to gustiness, but greater stability and speed in the machine are eliminating these difficulties.

Clouds introduce a difficulty of their own, apart from the point that has been already considered. It would seem at first sight as though a man would retain his sense of the vertical direction in any circumstances, but this is not so. Were a man placed inside a hollow vessel that was falling freely without air resistance, he would be entirely without sense of weight or direction, and the pilot of an aeroplane in an extensive mass of cloud is in much the same position. He cannot see any definite object, and apart from sight his sense of direction depends upon the reaction between him and the seat he is sitting on. So long as the motion is uniform this reaction is vertical, but any acceleration of the machine alters the direction and intensity of the reaction, and so confuses the sense of level. The same effect is produced upon a spirit-level or similar instrument, and so confusing is the effect that it is said the machine may almost be upside down without the pilot knowing it. It would seem as though a gyroscope might to some extent meet the difficulty. One result of this uncertainty of level is that astronomical observations for the determination of latitude and longitude are not possible unless the horizon can be seen, and thus the amount of the error produced by want of knowledge of the drift cannot be known.

Fog is to all intents and purposes simply a cloud touching the earth. Landing places for aviators have naturally been put in low, sheltered positions, partly because a shelter from wind is required, but probably chiefly because more or less of a dead level is necessary, and such flat places are more likely to be found at low altitudes. Such positions are especially liable to fog. The danger of a fog lies in its concealing the landing place and hiding from the pilot until the last moment his distance from the ground.

Thus it appears that the demand of the airman on the meteorologist is that he shall be able to forecast wind and fog, and, to a less extent, clouds, on the route the airman is proposing to follow. It has long been the business of the Meteorological Office to forecast wind, and a certain amount of precision has been attained. During last winter Major Taylor investigated the possibility of forecasting fog, and gave the results in lectures to the Royal Meteorological and Aeronautical Societies. His work constitutes 
a considerable advance in the investigation of this difficult subject. If we express the wind in terms of its two components, W. to E. and S. to N., the probable error of a forecast for each component is perhaps about ten miles an hour, and there is not much prospect of improving this; the estimate is for England and the Continent, but further south the conditions are much better.

I do not wish to emphasise the difficulties which lie in the way of regular air services, but they are there, and the first step towards overcoming them is to admit their existence.

W. H. DINES.

\section{NORTH-EAST SIBERIA. ${ }^{1}$}

THIS is a charming book of travel on a very interesting but seldom visited country-the far north-east of Siberia. One has to travel for changed since. The post reaches this miserable hamlet only once every four months. For three or four months, before the Kolyma breaks its ice at the end of May, and fishing can be resumed in June, the population lives in a state of semistarvation. "By the end of March all the store of fish is consumed, and the inhabitants begin to eat the food usually given to dogs, such as fishbones, entrails, and half-decayed fish." The last three or four months, before a fresh supply of provisions is brought by the boats coming from the south, most of the inhabitants have no salt and no flour, and are compelled to eat the fish raw, because cooked fish without salt seems to be most unpalatable. Under these conditions the physical and mental deterioration of the population is, of course, unavoidable.

In this spot the author remained four years,

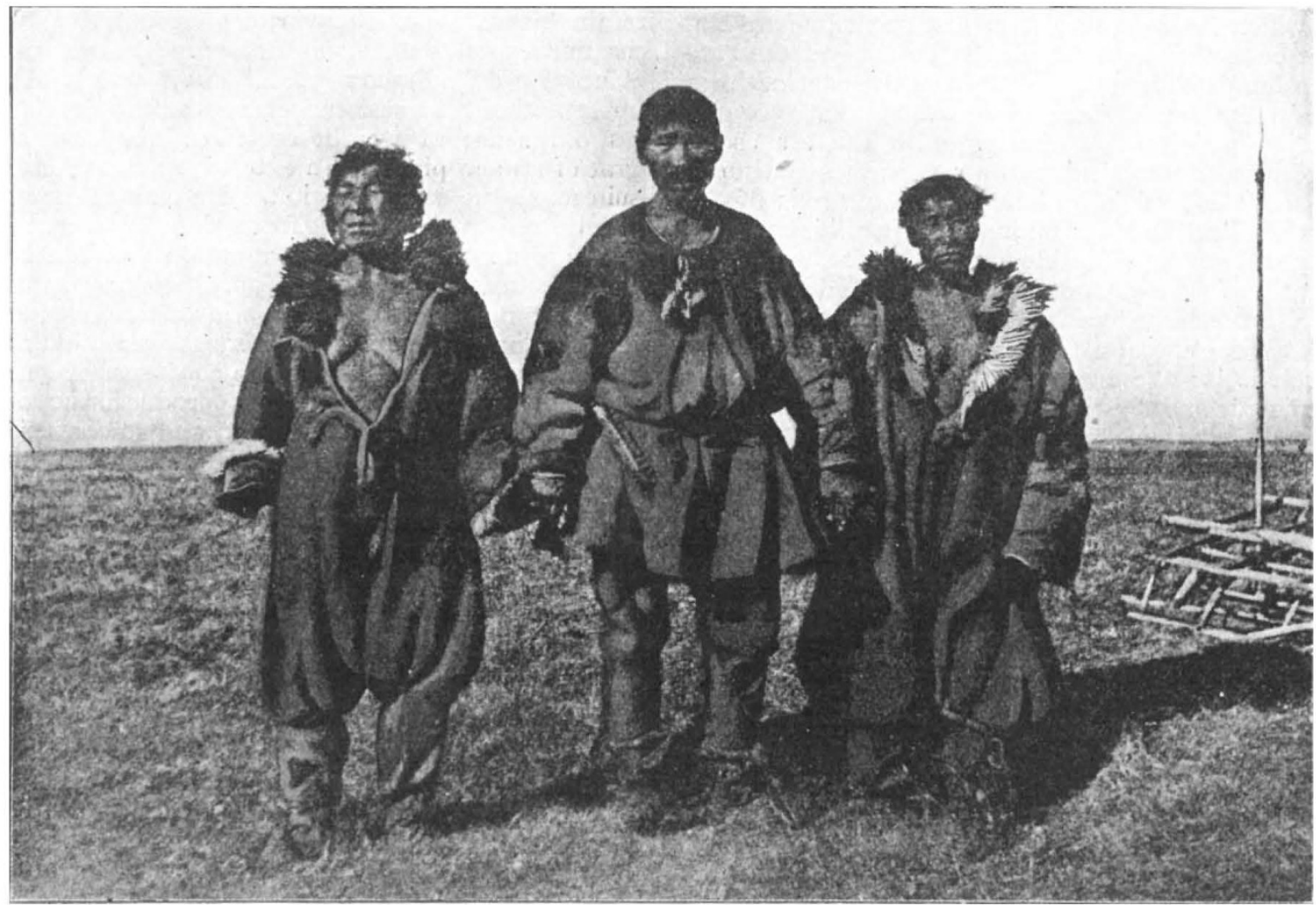

Chukchees. From "In Far North-East Siberia."

a month from Verkhoyansk, "the pole of cold," situated on the Upper Yana River, to reach Sredne-Kolymsk, "the queen of the country, consisting of twenty or thirty little flat-roofed loghuts scattered about on the left bank of the Kolyma." In this "town" the author was interned, by the Ministry of the Interior, in company with a dozen comrade students involved in "political disorders," and he stayed there four years.

That was thirty years ago; but nothing has 1 "In Far North-East Siberia." By I. W. Shklovsky ("Dioneo"). Translated bv L. Edwards and Z. Shklovsky. Pp. vii +264 . (London: Translated bv L. Edwards and Z. Shklovsky. Pp.
Macmillan and Co., Ltd., rgr6.) Price $8 s .6$. net.

NO. 249I, VOL. 997 and he devotes interesting pages to a good-natured description of how the little community of student-exiles constructed for themselves unburned-brick stoves (instead of the usual Yakute open hearth in the midst of the hut), and made their own provisions of fish and frozen cream for the winter, as well as candles from reindeer-fat for the long arctic night; all this work being done "amidst interminable metaphysical discussions." These pages have all the freshness of youth.

Towards the end of his internment at SredneKolymsk the author obtained permission to make a journey to Nijne-Kolymsk, at the mouth of the 